\title{
Serviços de saúde ofertados a mulheres vítimas de violência sexual no Brasil: revisão integrativa da literatura
}

\author{
Health services offered to women victims of sexual violence in Brazil: an integrative literature \\ review
}

Servicios de salud ofrecidos a mujeres víctimas de violencia sexual en Brasil: revisión integradora de la literatura

Recebido: 28/10/2021 | Revisado: 01/11/2021 | Aceito: 01/11/2021 | Publicado: 04/11/2021

\author{
Anna Beatryz Alves Mariano \\ ORCID: https://orcid.org/0000-0002-7798-7857 \\ Instituto Tocantinense Presidente Antônio Carlos, Brasil \\ E-mail: beatryz2@hotmail.com \\ Claudia Cristinne Gomes Cardoso \\ ORCID: https://orcid.org/0000-0001-7251-5626 \\ Instituto Tocantinense Presidente Antônio Carlos, Brasi \\ E-mail: claudiacristinneg@gmail.com \\ Evellyn Souza Ramos \\ ORCID: https://orcid.org/0000-0002-7735-9586 \\ Instituto Tocantinense Presidente Antônio Carlos, Brasil \\ E-mail: evellynsouzaramos@yahoo.com.br \\ Mariana do Prado Borges \\ ORCID: https://orcid.org/0000-0002-7032-8920 \\ Instituto Tocantinense Presidente Antônio Carlos, Brasil \\ E-mail: marianapb96@hotmail.com \\ Ana Mackartney de Souza Marinho \\ ORCID: https://orcid.org/0000-0002-9497-5153 \\ Instituto Tocantinense Presidente Antônio Carlos, Brasil \\ E-mail: mackartney@hotmail.com
}

\begin{abstract}
Resumo
Objetivo: Conhecer os serviços de saúde oferecidos a mulheres vítimas de violência sexual no Brasil. Metodologia: Trata-se de uma revisão integrativa que buscou literaturas entre os anos 2010 a 2020, através dos descritores "violência contra a mulher", "estupro" e "serviços de saúde da mulher", pesquisados nas plataformas LILACS, MEDLINE, Coleciona SUS e CUMED, que tratam do cenário brasileiro; tendo como idioma português/ inglês/ espanhol; disponíveis na íntegra de forma gratuita; que abordassem violência sexual, tipos de serviços ofertados, suas dificuldades e potencialidades. Resultados e Discussão: Através das buscas pelos descritores obteve-se 243 artigos pré-selecionados. Após leitura dinâmica dos artigos, sob a luz dos objetivos e da questão norteadora da pesquisa, obteve-se um total de 58 artigos finais. Os artigos contemplavam os tipos de serviços de saúde ofertados, falhas na identificação dos casos, ausência de fluxo de atendimento padronizado, subnotificação e necessidade da melhor capacitação profissional para manejar situações de violência sexual conta mulheres. Conclusão: Evidenciou-se lacunas na identificação dos casos de violência sexual, no acolhimento e atendimento, tanto no âmbito da saúde quanto no judiciário. Notou-se ainda, que não há um fluxo atendimento claro tanto para os profissionais quanto para as usuárias preconizado a nível nacional ou protocolos que facilitem o manejo individualizado dos casos. A violência sexual contra a mulher precisa ser debatida desde a graduação, para melhor capacitar os profissionais a fim de garantir a eficácia das redes de atendimento em todas as suas esferas.
\end{abstract}

Palavras-chave: Violência sexual; Mulher; Serviços de saúde.

\begin{abstract}
Objective: To know the health services offered to women victims of sexual violence in Brazil. Methodology: This is an integrative review that searched literature between 2010 and 2020, through the descriptors "violence against women", "rape" and "women's health services", searched in LILACS, MEDLINE, Coleciona SUS and CUMED platforms, dealing with the Brazilian scenario; in Portuguese, English and Spanish, available in full, free of charge, that addressed sexual violence, types of services offered, their difficulties and potentialities. Results and Discussion: Through searches by descriptors we obtained 243 pre-selected articles. After a dynamic reading of the articles, under the light of the objectives and the research guiding question, a total of 58 final articles were obtained. The articles contemplated the types of health services offered, failures in the identification of cases, lack of a standardized flow of care, underreporting,
\end{abstract}


and the need for better professional training to handle situations of sexual violence against women. Conclusion: There were gaps in the identification of cases of sexual violence, in the reception and care, both in the health sector and in the judiciary. It was also noted that there is no clear flow of care for both professionals and users recommended at the national level or protocols that facilitate the individual management of cases. Sexual violence against women needs to be discussed since graduation in order to better train professionals to ensure the effectiveness of care networks in all its spheres.

Keywords: Sexual violence; Women; Health services.

\section{Resumen}

Objetivo: Conocer los servicios de salud ofrecidos a las mujeres víctimas de violencia sexual en Brasil. Metodología: Se trata de una revisión integradora que buscó literatura entre 2010 y 2020, a través de los descriptores "violencia contra la mujer", "violación" y "servicios de salud de la mujer", buscados en las plataformas LILACS, MEDLINE, Coleciona SUS y CUMED, que traten del escenario brasileño; que tengan como idioma el portugués/inglés/español; que estén disponibles en su totalidad de forma gratuita; que aborden la violencia sexual, los tipos de servicios ofrecidos, sus dificultades y potencialidades. Resultados y discusión: A través de las búsquedas por descriptores se obtuvieron 243 artículos preseleccionados. Tras la lectura dinámica de los artículos, a la luz de los objetivos y de la pregunta guía de la investigación, se obtuvo un total de 58 artículos finales. Los artículos contemplaban los tipos de servicios sanitarios ofrecidos, los fallos en la identificación de los casos, la falta de un flujo de atención estandarizado, la falta de denuncias y la necesidad de mejorar la formación de los profesionales para manejar las situaciones de violencia sexual contra las mujeres. Conclusión: Se evidenciaron lagunas en la identificación de los casos de violencia sexual, en el tratamiento y en la atención, tanto en el ámbito de la salud como en el judicial. Sin embargo, no existe un flujo de atención claro tanto para los profesionales como para los usuarios preconizados a nivel nacional o protocolos que faciliten el manejo individualizado de los casos. La violencia sexual contra las mujeres debe ser discutida desde la graduación, para formar mejor a los profesionales con el fin de garantizar la eficacia de las redes de atención en todos sus ámbitos.

Palabras-clave: Violencia sexual; Mujeres; Servicios sanitarios.

\section{Introdução}

A violência sexual é uma das mais cruéis violências de gênero que atravessa a história e persiste até os dias atuais. Atinge mulheres em todos os espaços sociais, como forma de violência simbólica e moral, aterroriza o imaginário destas provocando sentimento constate de insegurança. O ditame patriarcal inverte a responsabilização para as próprias mulheres que consequentemente se sentem humilhadas, envergonhadas e desonradas, ampliando assim as dimensões do trauma sofrido, o que muitas vezes ocasiona o silenciamento e a dificuldade em expor a situação aos profissionais de saúde (OMS, 2012).

Garcia, 2016 por meio de estudos revelou que 35\% das mulheres do mundo já foram vítimas de violência sexual e/ou física perpetrada pelo parceiro íntimo ou não. O que demonstra que uma a cada três mulheres já sofreram ao menos um episódio desses tipos de violência. No Brasil em 2015 o SINAN registrou 17.781 atendimentos a mulheres vítimas de estupro, correspondente a médias de 49 atendimento por dia ou mais de dois por hora.

A violência pode ocorrer nos mais diferentes cenários, como nas escolas, na delinquência urbana, nos domicílios, nos locais de trabalho, em qualquer local que possibilite vulnerabilidade, e ter diversas naturezas (violência física, negligência, violência psicológica e sexual e assédios sexual e moral).

Pela definição da Organização Panamericana de Saúde (OPAS):

"Qualquer ato sexual, tentativa de consumar um ato sexual ou outro ato dirigido contra a sexualidade de uma pessoa por meio de coerção, por outra pessoa, independentemente de sua relação com a vítima e em qualquer âmbito. Compreende o estupro, definido como a penetração mediante coerção física ou de outra índole, da vulva ou ânus com um pênis, outra parte do corpo ou objeto" (OPAS, 2021).

A cada dia mais, o sexo feminino e as pessoas negras tornam-se os maiores alvos de violência sexual no Brasil. Estudos evidenciaram que 15 a $71 \%$ das mulheres em algum momento de suas vidas já sofreram violência física e/ou sexual (OMS, 2005).

No Brasil, a violência contra as mulheres apresenta sérios problemas de saúde pública, por ser uma das principais causas de morbidade e mortalidade feminina. Portanto, se faz necessário esforço da sociedade para garantir a prevenção e seu efetivo 
enfrentamento (OMS, 2012).

Reconhecendo as grandes proporções do problema, vários países decretaram leis para criminalizar a violência sexual de todas as formas que ela pode ocorrer, como por exemplo a praticada pelo parceiro íntimo. Muitos destes países providenciam cada vez mais serviços legais, de saúde e sociais às mulheres que sofreram abusos. Entretanto, percebe-se poucos esforços voltados para a prevenção da violência sexual e doméstica. Os serviços bem planejados e adequadamente implantados continuarão tendo uma importância vital, mas ainda assim, deve-se atuar na prevenção da violência sexual, desta forma, seria possível reduzir a carga de sofrimento, além dos custos humanos, econômicos e de saúde pública. Os serviços de atendimento e os esforços de prevenção primária às vítimas devem ser acertadamente documentados para que possam ser avaliados quanto á sua eficácia (OMS, 2012).

$\mathrm{Na} 8^{\circ}$ Conferência Nacional de Saúde (CNS), a qual tinha como tema central "Saúde para todos no ano 2000", foi elaborado metas e ações para o atendimento primário à mulher brasileira. O Ministério da Saúde elaborou o Programa de Assistência Integral à Saúde da Mulher (PAISM), que tem como diretrizes gerais a incorporação efetiva da integralidade da assistência a mulher desde a adolescência, através da prática educativa, assegurando assim o conhecimento necessário para que tenha maior controle sobre sua saúde. Por meio deste, os serviços passariam a promover, proteger e recuperar a saúde, baseandose na prestação de assistência clínica integral e educativa, que seja voltada para a assistência ao cuidado da mulher de maneira holística (Ministério da Saúde, 2010b).

Mediante os fatores já mencionados, faz-se necessário organizar os serviços de saúde da prevenção, promoção e assistência. Com base nisso, as leis que vigoram dentro da atenção em saúde, que resguardam a saúde da mulher acerca da violência sexual são:

Lei $\mathrm{n}^{\circ}$ 10.778/2003, que instituiu a notificação compulsória de violência contra a mulher (Lei $\mathrm{N}^{\circ}$ 10.778, de 24 de novembro de 2003, 2003);

Portaria n. 936/GM/MS de 18 de maio de 2004, dispõe sobre a estruturação da Rede Nacional de Prevenção da Violência e Promoção da Saúde e a implantação e implementação de Núcleos de Prevenção à Violência em Estado e Municípios (Ministério da Saúde, 2004);

Portaria MS/GM nº 1.356, de 23 de junho de 2006, que implanta o Sistema de Vigilância de Violências e Acidentes em Serviços Sentinela - Viva (Ministério da Saúde, 2006);

Política Nacional de Promoção da Saúde/2010 (Ministério da Saúde, 2010);

Norma Técnica de Prevenção e Tratamento dos Agravos Resultantes da Violência Sexual Contra Mulheres e Adolescentes (Ministério da Saúde, 2012);

Lei $\mathrm{N}^{\circ} 12.845$, de $1 \%$ /08/2013 Dispõe sobre o atendimento obrigatório e integral de pessoas em situação de violência sexual (Lei $\mathrm{n}^{\circ} 12.845$, de $1^{\circ}$ de agosto de 2013, 2013);

Política de Atenção Integral à Saúde da Mulher, Linha de Cuidado para a Atenção à Saúde de Crianças, Adolescentes e suas Famílias em Situação de Violências, dentre outros (Ministério da Saúde, 2010b).

A Lei $\mathrm{n}^{\circ}$ 12.845/2013 dispõe sobre o atendimento integral e obrigatório de pessoas em situação de violência sexual. Desta feita, as instituições devem garantir todas as etapas do atendimento, medidas preventivas, emergenciais, acompanhamento pós, reabilitação, possíveis tratamentos em situações de agravo e demais impactos psicológicos e físicos, bem como o aborto legal caso seja a escolha da vítima. É estabelecido pelo decreto $n^{\circ}$ 7.958/2013 diretrizes para atender vítimas de violência sexual por profissionais de segurança pública e da rede de atendimento do SUS e a Norma Técnica Prevenção e Tratamento de Agravos Resultantes da Violência Sexual Contra as Mulheres e Adolescente do Ministério da Saúde (Lei ${ }^{\circ} 12.845$, de $1^{\circ}$ de agosto de 2013, 2013).

Os Gestores nas três esferas de poder têm obrigações decisivas na organização e suprimento de insumos das redes 
integradas de atendimento, além da sua divulgação global. Deve ser exposto uma lista de contatos com acesso por todos os colaboradores e usuárias com endereço e telefone das instituições componentes da rede.

Na saúde pública a conduta permeia ações coletivas, interdisciplinares e interinstitucionais, alcançando o desempenho e eficácia em cada função dentro da rede. Problemas de acesso e manejo dos casos devem ser expostos e debatidos periodicamente, com intuito de levantar instrumentos de avaliação, apresenta-los aos gestores e promover melhores condições gerais de trabalho para os profissionais e garantir atenção integral às vítimas e seus familiares (Ministério da Saúde, 2012).

A abordagem na perspectiva de saúde pública foca no indivíduo como um todo e não somente em uma parte da problemática. Abrange todos os meios que serão afetados por esse delito, por isso tem uma abordagem interdisciplinar e multissetorial. Objetiva providenciar o máximo de benefício para um maior número de pessoas além de uma melhor atenção e segurança para as populações (OMS, 2012).

Considerando a relevância do tema supracitado tanto para fins de saúde pública, para elencar suas demandas e potencialidades dentro dos sistemas de saúde quanto, para importância de dar maior visibilidade as dificuldades enfrentadas por mulheres vitimadas, a seguinte questão norteou o desenvolvimento dessa pesquisa: Quais serviços de saúde são oferecidos a mulheres vítimas de violência sexual no Brasil? Sendo assim, o trabalho tem como objetivo conhecer os serviços de saúde oferecidos a mulheres vítimas de violência sexual no Brasil.

\section{Metodologia}

Refere-se a uma revisão integrativa da literatura. Esse tipo de pesquisa tem por objetivo reunir achados de estudos desenvolvidos mediante diferentes metodologias, permitindo aos revisores sintetizar resultados sem ferir a filiação epistemológica dos estudos empíricos incluídos (Soares et al., 2014).

É um método que permite sintetizar resultados obtidos em pesquisas sobre determinado tema ou questão, de maneira sistemática, ordenada e abrangente. É denominada integrativa porque fornece informações mais amplas sobre um assunto, constituindo, assim, um corpo de conhecimento (Gonçalves, 2005).

Com a diversidade de informações geradas advindas do acesso global a internet e mundo digital, tem se tornado cada vez mais nítido a necessidade do desenvolvimento de artifícios no contexto do embasamento científico, capazes de elucidar melhor a utilização dessas metodologias em seus determinados campos de atuação na área da saúde. A revisão integrativa permite a incorporação dos resultados obtidos na prática. Incentivada progressivamente pelo instrumento da Prática Baseada em Evidências (PBE) (Souza; Silva; Carvalho, 2010).

Apresentam-se como etapas da construção da revisão integrativa: Primeiro - escolher um tema e estabelecer a hipótese ou questão de pesquisa; Segundo - buscar na literatura, selecionar estudos conforme base de dados escolhidas, definir critérios de inclusão e exclusão; Terceiro - organizar os estudos categoricamente, determinar as informações relevantes a serem extraídas, formular seu banco de dados; Quarto - avaliar estudos selecionados na revisão; Quinto - interpretar resultados; Sexto - realizar síntese do conhecimento adquirido com a compilação dos resultados obtidos com detalhamento e apresentação da revisão (Mendes; Silveira; Galvão, 2008).

Nesta pesquisa em sua primeira etapa foi elaboro o seguinte tema norteador: Conhecer os tipos de serviços de saúde oferecidos a mulheres vítimas de violência sexual no Brasil.

Para segunda etapa foi realizada a busca na literatura baseada nos seguintes descritores: violência contra mulher; serviços de saúde da mulher e estupro. Combinados pelos conectivos “AND” ou "OR”. Tendo como critérios de inclusão: Artigos publicados nas bases de dados Literatura Latino-Americana e do Caribe em Ciências da Saúde (LILACS), Medical Literature Analysis and Retrieval System Online (MEDLINE), Coleciona SUS e Centro Nacional de Informação de Ciências Médicas de 
Cuba (CUMED); entre os anos 2010 a 2020; que tratam do cenário brasileiro; tendo como idioma português/ inglês/ espanhol; disponíveis na íntegra de forma gratuita; que abordassem violência sexual, tipos de serviços ofertados, suas dificuldades e potencialidades.

Foram estabelecidos como critérios de exclusão: publicações que não estivessem dentro da periodicidade escolhida; que não fossem em português/ inglês/ espanhol; que não estivessem disponíveis na integra; artigos que não abordassem violência sexual/serviços da rede de atendimento à mulher; artigos que estivessem repetidos.

Ao aplicar o descritor "violência contra a mulher" tivemos o resultado de 1728 artigos. Aplicados os filtros base de dados, texto completo, assunto principal, ano de publicação. Utilizando as bases de dados LILACS, CUMED e COLECIONA SUS, obtivemos 923 artigos. Sendo: Coleciona SUS 71, CUMED 47, LILACS 837. Ao ser aplicado Assuntos principais Violência contra a mulher (861); delitos sexuais (100) estupro (18) Gravidez (12) Doenças sexualmente transmissíveis (11) aborto (11) Direito da mulher (33). Nos idiomas Inglês, Português e Espanhol. Nos anos de 2010 a 2020 obtivemos 662 artigos. Dada leitura exaustiva dos títulos embasada nos objetivos do estudo como critério de exclusão obteve-se (191).

Ao aplicar o descritor "estupro" foram encontrados 2067 artigos. Aplicados os filtros de base de dados, MEDLINE (19946), LILACS (84), COLECIONA SUS (3) e CUMED (1), obteve-se o resultado de (6582) artigos ao ser aplicado o filtro do ano de publicação 2010 a 2020, resultou (1880). Ao selecionar os idiomas inglês, português e espanhol. Ao aplicar o filtro de limite a opção feminino, obteve-se 1482 artigos. Estupro 1122, vítima de crime 320, violência por parceiro íntimo 36, transtorno de estresse pós-traumático 141, comportamento sexual 109, assédio sexual 17, acesso ao serviço de saúde 16, notificação de abuso 10. Ao ser aplicado esses assuntos principais obteve-se um total de 1252 artigos. Ao aplicar o filtro de país como brasil e américa do Sul (45). Dada leitura exaustiva dos títulos embasada nos objetivos do estudo como critério de exclusão obteve-se (20).

Ao aplicar o descritor Serviços de saúde da mulher obteve-se 4.981 artigos. Os filtros utilizados foram Texto completo; base de dados; assunto principal; idioma. Ao ser aplicado o filtro de base de dados MEDLINE (3.875); LILACS (570); Coleciona SUS (1) obteve-se 4.462 artigos. Assuntos principais: Serviços de saúde da mulher (3.118); Acesso ao serviço de saúde (383); Mulheres maltratadas (134); Qualidade da assistência à saúde (100); Idiomas Inglês (2646); Português (306); Espanhol (180). Entre os anos 2010 a 2020 (822). Dada leitura exaustiva dos títulos embasados nos objetivos do estudo como critério de inclusão e exclusão obteve-se (31).

Após a realização das buscas por meio das bases de dados supracitadas e aplicação dos filtros utilizados como critério de inclusão e exclusão dos artigos (242) pré-selecionados, realizou-se uma leitura dinâmica dos artigos, sob a luz dos objetivos e da questão norteadora da pesquisa, onde obteve-se um total de 58 artigos finais selecionados.

Para terceira etapa dessa pesquisa foi elaborado o instrumento de coleta de dados, onde será realizado o fichamento das informações extraídas nos artigos incluídos e que serão trabalhados.

Para quarta etapa será realizada leitura exaustiva dos artigos selecionados como aptos a contribuir com os objetivos de estudo. Deve-se presar pela avaliação imparcial dos resultados encontrados.

Na quinta etapa cabe ao pesquisador ultrapassar mera descrição dos resultados, contribuindo assim com algo novo que pode compreender sobre o assunto (Gonçalves, 2005).

Para sexta e última etapa dessa pesquisa esperasse a apresentação dos resultados por meios de tabelas e/ou quadros, bem como discussão dos achados literários pertinentes ao tema trabalhado.

\section{Resultados e Discussão}

Na pesquisa inicial, por meio da aplicação dos descritores violência contra a mulher, estupro e serviços de saúde da 
mulher, obteve-se 243 artigos pré-selecionados. Após realização de leitura através dos critérios de inclusão e exclusão dos títulos e resumos, norteados pelos objetivos do estudo e da pesquisa obteve-se 58 artigos, conforme Quadro 1. Sendo estes, apenas um em inglês, um em espanhol e os demais em português.

Quadro 1: Distribuição dos artigos considerando ano de publicação e periódico.

\begin{tabular}{|c|c|c|}
\hline Ano & Título do artigo & Revista \\
\hline 2010 & $\begin{array}{c}\text { Violência sexual: experiência do Programa de Atendimento às Vítimas de Violência } \\
\text { Sexual PRAVIVIS, do Hospital Geral de Caxias do Sul, RS, Brasil. }\end{array}$ & Rev. AMRIGS \\
\hline 2011 & $\begin{array}{c}\text { Características das mulheres violentadas sexualmente e da adesão ao seguimento } \\
\text { ambulatorial: tendências observadas ao longo dos anos em um serviço de referência em } \\
\text { Campinas, São Paulo, Brasil }\end{array}$ & Cad. saúde pública \\
\hline 2013 & $\begin{array}{c}\text { Violência sexual: estudo descritivo sobre as vítimas e o atendimento em um serviço } \\
\text { universitário de referência no Estado de São Paulo, Brasil }\end{array}$ & Cad. saúde pública \\
\hline 2013 & Encaminhamentos à mulher em situação de violência conjugal & O mundo da saúde \\
\hline 2013 & $\begin{array}{c}\text { Significado da capacitação profissional para o cuidado da mulher vítima de violência } \\
\text { conjugal. }\end{array}$ & Esc Anna Nery \\
\hline 2013 & Mulheres em situação de violência: entre rotas críticas e redes intersetoriais de atenção. & Rev. de medicina \\
\hline 2013 & $\begin{array}{l}\text { Necessidades assistenciais de mulheres que denunciam na delegacia de polícia a vivência } \\
\text { da violência }\end{array}$ & AQUICHAN \\
\hline 2014 & Enfrentamento da violência contra a mulher: articulação intersetorial e atenção integral & Saúde Soc \\
\hline 2014 & A verdade do estupro nos serviços de aborto legal no Brasil & Rev. bioét. \\
\hline 2014 & $\begin{array}{l}\text { Conhecimento de enfermeiras em unidades de saúde sobre a assistência à mulher vítima } \\
\text { da violência }\end{array}$ & Revista Baiana de Enfermagem \\
\hline 2015 & $\begin{array}{l}\text { Rede de atenção à mulher em situação de violência: os desafios da transversalidade do } \\
\text { cuidado }\end{array}$ & Rev. Eletr. Enf \\
\hline 2015 & Vítimas de violência sexual atendidas em um serviço de referência & Cogitare Enferm \\
\hline 2015 & Significados acerca da notificação da violência contra a mulher: estudo descritivo & Online braz j nurs \\
\hline 2015 & Violência sexual contra mulheres: a prática de enfermeiros & Rev Rene \\
\hline 2015 & Notificações de violência sexual contra a mulher no brasil & Rev Bras Promoç Saúde \\
\hline 2015 & Políticas públicas e violência contra a mulher: a realidade do sudoeste goiano & Rev. SPAGESP \\
\hline 2015 & Formação profissional e notificação da violência contra a mulher & Revista Baiana de Enfermagem \\
\hline 2015 & Alterações autobiográficas em mulheres vitimadas atendidas pela rede de acolhimento & Ver. Subjetividades \\
\hline 2016 & $\begin{array}{l}\text { Intencionalidade da ação de Cuidar mulheres em situação de violência: contribuições para } \\
\text { a Enfermagem e Saúde }\end{array}$ & Escola Anna Nery \\
\hline 2016 & $\begin{array}{l}\text { Indicadores da violência contra a mulher provenientes das notificações dos serviços de } \\
\text { saúde de minas gerais-brasil }\end{array}$ & Texto Contexto Enfermagem \\
\hline 2016 & $\begin{array}{l}\text { Os sentidos produzidos para a violência contra as mulheres a partir da perspectiva dos } \\
\text { profissionais da delegacia especializada de atendimento à mulher de betim-mg }\end{array}$ & Psicologia em revista \\
\hline 2016 & Eficácia de um programa de intervenção para mulheres vítimas de abuso sexual & Terapia Psicológica \\
\hline 2016 & $\begin{array}{c}\text { Estupro e gravidez: Relatos das vivências de mulheres antes e } \\
\text { após o desfecho da gestação }\end{array}$ & Estudos de Psicologia \\
\hline 2016 & A magnitude invisível da violência contra a mulher & Epidemiol. Serv. Saude \\
\hline 2016 & Violência contra mulher: acolhimento na estratégia saúde da família. & Ciência, Cuidado e Saúde \\
\hline 2016 & $\begin{array}{c}\text { Características epidemiológicas de la violencia contra la mujer en el Distrito Federal, } \\
\text { Brasil, 2009-2012 }\end{array}$ & Epidemiol. Serv. Saude \\
\hline 2016 & Bioética e atendimento a mulheres vítimas de violência sexual. & Acta Bioethica \\
\hline 2016 & $\begin{array}{l}\text { Instrumentos para articulação da rede de atenção às mulheres em situação de violência: } \\
\text { construção coletiva. }\end{array}$ & Rev. gaúch. Enferm \\
\hline 2017 & $\begin{array}{c}\text { Violência contra a mulher: uma análise dos } \\
\text { Desdobramentos da denúncia na cidade de vitória/es. }\end{array}$ & $\begin{array}{l}\text { Seminário Internacional Fazendo Gênero } 11 \& 13 \text { th } \\
\text { Women's Worlds Congress }\end{array}$ \\
\hline 2017 & Redes de apoio social para mulheres em situações de violência por um parceiro íntimo & Portal de Revista de Enfermagem \\
\hline 2017 & $\begin{array}{l}\text { Violência contra mulher em contexto de vulnerabilidade social na Atenção Primária: } \\
\text { registro de violência em prontuários }\end{array}$ & $\frac{\text { Revista brasileira de medicina de família e }}{\text { comunidade }}$ \\
\hline
\end{tabular}


Research, Society and Development, v. 10, n. 14, e344101422427, 2021

(CC BY 4.0) | ISSN 2525-3409 | DOI: http://dx.doi.org/10.33448/rsd-v10i14.22427

\begin{tabular}{|c|c|c|}
\hline 2017 & $\begin{array}{c}\text { Potencialidades e limites da visita domiciliar para identificar e abordar mulheres em } \\
\text { situação de violência }\end{array}$ & $\underline{\text { Ciência, cuidado e saúde }}$ \\
\hline 2017 & $\begin{array}{l}\text { Percepções dos profissionais de uma rede intersetorial sobre o atendimento a mulheres em } \\
\text { situação de violência }\end{array}$ & Interface (Botucatu): comunicação, saúde, educação \\
\hline 2017 & $\begin{array}{l}\text { O sofrimento psíquico no cotidiano de mulheres que vivenciaram a violência sexual: } \\
\text { estudo fenomenológico }\end{array}$ & Escola Anna Nery \\
\hline 2017 & Gravidez decorrente de violência sexual: revisão sistemática da literatura & $\frac{\text { Arquivos brasileiros de psicologia (Rio de Janeiro. }}{\underline{2003)}}$ \\
\hline 2017 & $\begin{array}{c}\text { Estupro no Brasil: vítimas, autores, fatores situacionais e evolução das notificações no } \\
\text { sistema de saúde entre } 2011 \text { e } 2014\end{array}$ & e \\
\hline 2018 & $\begin{array}{c}\begin{array}{c}\text { Experiências de mulheres em situação de violência em busca de atenção no setor saúde e } \\
\text { na rede intersetorial }\end{array} \\
\end{array}$ & Revista Interface (Botucatu, Online) \\
\hline 2018 & Violência contra mulher: concepções e práticas de profissionais de serviços públicos & Revista Estudos Interdisciplinares em Psicologia \\
\hline 2018 & $\begin{array}{c}\text { Violência contra a mulher: como os profissionais na atenção primária à saúde estão } \\
\text { enfrentando esta realidade? }\end{array}$ & Revista Saúde e Pesquisa \\
\hline 2018 & Abordagem a mulheres em situação de violência sexual na perspectiva da bioética & $\underline{\text { Acta bioethica }}$ \\
\hline 2018 & Violência sexual na região do $\mathrm{ABC}$ Paulista: retrato de 142 casos & $\underline{\mathrm{ABCS} \text { health sciences }}$ \\
\hline 2018 & Atuação da enfermagem na conservação da saúde de mulheres em situação de violência & REME: revista mineira de enfermagem \\
\hline 2018 & Representações sociais da violência contra a mulher: atuação multiprofissional social & $\underline{\text { Summa psicológica UST }}$ \\
\hline 2019 & $\begin{array}{l}\begin{array}{l}\text { Violência por parceiro íntimo em abuso de álcool perpetrada contra mulheres no } \\
\text { climatério }\end{array} \\
\end{array}$ & $\underline{\text { Revista de enfermagem da UFSM }}$ \\
\hline 2019 & Notificações de violências contra a mulher adulta no Estado de São Paulo em 2014 & BEPA. Boletim epidemiológico paulista \\
\hline 2019 & Mulheres vítimas de abuso sexual em um município da Amazônia & Rev. Ciênc. Plur \\
\hline 2019 & Violência física ou sexual contra a mulher no Piauí, 2009-2016. & J. Health Biol. Sci. (Online) \\
\hline 2019 & $\begin{array}{l}\text { Direitos sexuais e reprodutivos de mulheres em situação de violência sexual: o que dizem } \\
\text { gestores, profissionais e usuárias dos serviços de referência? }\end{array}$ & Saúde Soc \\
\hline 2020 & $\begin{array}{c}\text { Produções científicas brasileiras em psicologia sobre violência contra mulher por parceiro } \\
\text { íntimo }\end{array}$ & Psicologia, ciência e profissão \\
\hline 2020 & $\begin{array}{c}\text { Perfil dos casos de violência contra a mulher notificados no município de Eldorado do } \\
\text { Sul, Rio Grande do Sul, entre } 2010 \text { e } 2018\end{array}$ & Escola de Saúde Pública do Rio Grande do Sul \\
\hline 2020 & $\begin{array}{l}\text { Psicólogas nos serviços especializados de atendimento às mulheres em situação de } \\
\text { violência }\end{array}$ & Psicologia em Estudo \\
\hline 2020 & $\begin{array}{c}\text { Desafios para implantação da cadeia de custódia para as vítimas de estupro no Distrito } \\
\text { Federal }\end{array}$ & Escola Anna Nery Revista Enfermagem \\
\hline 2020 & Violência contra as mulheres na prática de enfermeiras da atenção primária à saúde & Escola Anna Ney Revista Enfermagem \\
\hline 2020 & Desvelando as estratégias de enfrentamento da violência conjugal utilizadas por mulheres & Texto \& Contexto Enfermagem \\
\hline 2020 & $\begin{array}{l}\text { A percepção da vítima de violência sexual quanto ao acolhimento em um hospital de } \\
\text { referência no Paraná }\end{array}$ & $\begin{array}{l}\text { Revista de Pesquisa: Cuidado é Fundamental Online } \\
\text { / Journal of Research: Fundamental Care Online }\end{array}$ \\
\hline 2020 & A violência contra a mulher no sistema único de saúde & $\begin{array}{c}\text { Revista: Revista de Pesquisa: Cuidado é } \\
\text { Fundamental Online / Journal of Research: } \\
\text { Fundamental Care Online }\end{array}$ \\
\hline 2020 & Violence against women during covid-19 pandemic restrictions. & BMJ \\
\hline 2020 & Mulheres vítimas de abuso sexual em um município da Amazônia & Rev. Ciênc. Plur \\
\hline
\end{tabular}

Fonte: Autores.

Na identificação de periódicos, a Revista Escola Anna Nery, destaca-se nos números de produções cientificas, apresentando 5 artigos a respeito da temática trabalhada.

Com relação a distribuição de publicações por região do Brasil constatou-se a região Sudeste com maior número de publicações, apresentando 35,71\% (20), seguida da região Nordeste com 28,57\% (16), Sul com 25\% (14), Centro-Oeste com $8,93 \%$ (5) e região Norte com 1,79\% (1), conforme Figura 1. O presente estudo ainda contou com 1 publicação dos Estados Unidos e 1 publicação da Espanha. 
Figura 1: Artigos subdivididos por região conforme critérios de inclusão e exclusão.

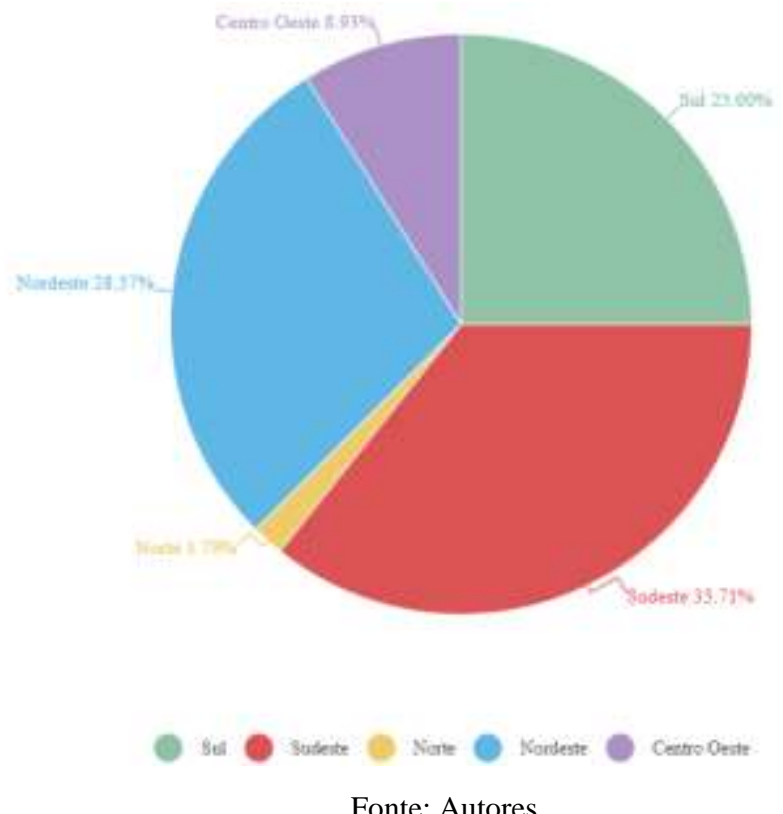

Fonte: Autores.

De acordo com o intervalo temporal estabelecido de 2010 a 2020 e os critérios de interesse para esta pesquisa, pode-se perceber que os anos de 2016 e 2020 foram os anos com maior número de publicações, totalizando 10 artigos em ambos os anos. Já os anos de 2010 e 2011 apresentaram o menor número publicações, 1 por ano, conforme Tabela 1.

Tabela 1: Quantidade de publicações por ano.

\begin{tabular}{c|c} 
ANO & QUANTIDADE DE PUBLICAÇÕES \\
\hline $\mathbf{2 0 1 0}$ & 1 \\
$\mathbf{2 0 1 1}$ & 1 \\
$\mathbf{2 0 1 3}$ & 5 \\
$\mathbf{2 0 1 4}$ & 3 \\
$\mathbf{2 0 1 5}$ & 8 \\
$\mathbf{2 0 1 6}$ & 10 \\
$\mathbf{2 0 1 7}$ & 8 \\
$\mathbf{2 0 1 8}$ & 8 \\
$\mathbf{2 0 1 9}$ & 4 \\
$\mathbf{2 0 2 0}$ & 10 \\
& Fonte: Autores.
\end{tabular}

Afim de ampliar e melhorar a qualidade dos serviços de atenção as mulheres em situação de violência, foi instituída uma rede de atendimento que se refere a atuação articulada entre instituições governamentais, não governamentais e comunidade. A criação dessa rede de atendimento leva em consideração a rota crítica, que nada mais é do que a trajetória percorrida pelas mulheres em busca de encontrar soluções no Estado e nos serviços frente a situação de violência. Essa busca é marcada por idas e vindas, irresolutas e que culminam na revitimização e no desgaste emocional (Ministério da Saúde, 2012).

A rede de atendimento, a nível governamental, é composta por:

Centros de Referência: atuam na esfera de atendimento psicológico e social e na orientação a encaminhamentos jurídicos, servindo como articulador das instituições e serviços que interagem dentro da rede.

Casas-Abrigo: locais sigilosos e temporários, seguros que dispõem moradia protegida e atendimento integral a mulheres em risco de vida iminente em face da violência doméstica, pelo tempo necessário até que essas mulheres possam retomar a autonomia de suas vidas. 
Delegacias Especializadas de Atendimento à Mulher (DEAM's): unidades especializadas da polícia civil, que realizam ações de cunho preventivo e repressivo, conforme apuração, investigação e enquadramento legal. Como exemplo, emitem expedição de medidas protetivas de urgência ao juiz em até 48 horas.

Defensoria da Mulher: fornecer assistência jurídica, orientar e encaminhar as vítimas. É responsável pela defesa das cidadãs sem meios econômicos de arcar com custos advocatícios.

Juizado de Violência Doméstica e Familiar contra a Mulher: órgão da Justiça Ordinária de competência cível e criminal, criado para o processo, julgamento e a execução das causas decorrente da prática de violência doméstica e familiar contra a mulher.

Central de Atendimento à mulher - ligue 180: canal criado para receber denúncias e orientar mulheres em situação de violência. A ligação é gratuita e funciona 24 horas, com atendentes capacitadas permanentemente em questões de gênero, legislação e políticas governamentais para mulheres.

Ouvidoria: canal de acesso e comunicação direta para fortalecer os diretos de cidadã.

Centros de referência da Assistência (CRAS) e Centros de Referência Especializado de Assistência Social (CREAS): são centros de caráter preventivo e protetivo, respectivamente, para famílias em condição de vulnerabilidade social e em situação de risco pessoal.

Serviço de Responsabilização e Educação do Agressor: responsável por acompanhar as penas e decisões determinadas pelo juízo competente. Dentre as atribuições estão: promover atitudes educativas, pedagógicas e grupos reflexivos com a perspectiva de gênero feminista e com a abordagem responsabilizante, bem como informações permanentes dos agressores através de relatórios e documento técnicos.

Polícia Civil e Militar: delegacia comum, que deve registrar toda e qualquer ocorrência advindas de mulher vítima de violência e encaminha-las aos serviços da rede.

Instituto Médico Legal: atua na coleta ou validação de provas que serão necessárias para o processo judicial e a condenação do agressor.

Serviços de Saúde voltados para o atendimento dos casos de violência sexual: presta assistência multiprofissional e social as vítimas de violência sexual, bem como na interrupção da gravidez, conforme prevista em lei.

Como preconizado pela Norma Técnica para Atenção Humanizada às Pessoas em Situação de Violência Sexual, o atendimento deve ser ofertado por uma equipe multidisciplinar, formada basicamente por: médico(a), enfermeiro(a), técnico(a) em enfermagem, assistente social e psicólogo. Poderá ainda ser constituída por outros profissionais como o farmacêutico (a) (Ministério da Saúde, 2015).

Cabe aos gestores de saúde municipal, estadual e federal implantar e implementar serviços de referência, assim como avaliar os mecanismos de ações desenvolvidas por eles.

Segundo Rosa et.al, 2018, 98,6\% dos municípios brasileiros declararam possuir serviços socioassistenciais a mulheres vítimas de abuso sexual. Entretanto, menos da metade, declararam oferecer serviços como o "Serviço de Apoio e Orientação aos Indivíduos e famílias Vítimas de Violência" (45,6\%) e o "Serviço de Enfrentamento à Violência, Abuso e Exploração Sexual de Crianças e Adolescentes e suas Famílias" (39\%).

No território brasileiro, os serviços de saúde previstos por lei para mulheres vítimas de violência sexual, não são ofertados integralmente e de forma homogênea pelo país. Os Centros de Referência e os Programas Especializados são mais localizados nos grandes centros urbanos, demonstrando assim uma falha na integralidade e universalidade da assistência.

No município de Campinas, segundo Oshikata et.al, 2011, há o Centro de Atenção Integral à Saúde da Mulher (CAISM) da Universidade Estadual de Campinas (UNICAMP), o qual é um suporte hospitalar terciário de referência regional para o atendimento de mulheres que sofrem violência sexual. O Centro oferece uma equipe multidisciplinar, composta por: médicos 
ginecologistas, infectologistas, enfermeiros, além de psicólogas e assistentes sociais que prestam serviços juntamente com a equipe médica. Estruturado em atendimentos de urgência, emergência e ambulatorial, 24 horas.

Segundo Madi et. al, 2010, há um programa especializado em atender vítimas de violência sexual no munícipio Caxias do Sul chamado Programa de Atendimento às Vítimas de Violência Sexual (PRAVIVIS), que tem como objetivo amparar as vítimas através dos atendimentos clínicos e da assistência ao aborto legal. Através dos seguintes serviços oferecidos: infectologia, ginecologia, obstetrícia, ultrassonografia, anestesia, assistente social, psicologia e enfermagem.

Nos demais artigos utilizados para o estudo foram expostos os atendimentos por parte das Equipes de Saúde da Família (ESF) nas Unidades Básicas de Saúde (UBS), ressaltando a heterogenia dos serviços especializados oferecidos pelas diferentes regiões do país. Além de apontar a Atenção Primária de Saúde (APS), como importante porta de entrada para atender essa demanda.

No estado do Tocantins, existe o Serviço de Atenção Especializada às Pessoas em Situação de Violência Sexual (SAVIS) que está ativo nos municípios de Palmas e Porto Nacional e em processo de implantação em Gurupi, Araguaína e Paraíso. Esse serviço tem como finalidade promover a atenção integral e integrada às pessoas em situação de violência sexual, a partir de atendimento de urgência, emergência e ambulatorial com uma equipe multiprofissional capacitada, incluindo médico, enfermeiros, assistentes sociais, psicólogos e outros. O Hospital e Maternidade Dona Regina (HMDR) em Palmas é referência neste tipo de atendimento para os demais munícipios do Tocantins. Esse centro atende todo o estado e tem parceria com as delegacias de polícia e os postos de saúde municipais. Em caso de gravidez decorrente da violência, o programa realiza a interrupção ou o acompanhamento pré-natal. $\mathrm{O}$ atendimento é realizado de forma humanizada e segura, evitando a revitimização (Secretária da Saúde, 2012).

No ano de 2015, foi estabelecida a Portaria Interministerial n ${ }^{\circ}$ 288/2015 que rege que o atendimento na emergência à criança e à mulher vítima de violência sexual seja realizado por equipe própria e capacitada, esta deverá ser composta por médico ginecologista, enfermeiro, psicólogo e assistente social. Com isso, a fim de evitar a peregrinação das vítimas aos órgãos de saúde e justiça, foi estabelecido no Distrito Federal a Cadeia de Custódia em ambiente hospitalar, que tem como intuito adequar o processo de coleta, armazenamento e registro do material biológico que restou como indício da violência sexual. (Arrais et al, 2020)

Tal processo está previsto para ser instalado em todo o Brasil, mas em primeiro momento será instalado em cinco hospitais públicos do Distrito Federal. Segundo o estudo as etapas utilizadas no atendimento a vítima de violência sexual são: Acolhimento, Classificação de Risco, Preenchimento da Notificação Compulsória, Medicações, Atendimento Clínico, Ecografia e dar alta. Um ponto que chama atenção nesse artigo são os profissionais que atuam nesse âmbito desconhecerem as normas técnicas e protocolos clínicos que amparam a mulher vítima de violência sexual nas emergenciais hospitalares. (Arrais et al, 2020)

Como meio de comunicação digital para facilitar o acesso à informação e divulgação sobre os programas de enfrentamento a violência contra a mulher, a Fundação de População das Nações Unidas (UNFPA), criou a plataforma mulher segura, onde é possível realizar a busca por canais de apoio em todo o Brasil. Nela estão reunidos os principais serviços ofertados pelos Estados e Municípios. Além de facilitar o acesso aos serviços especializados, apresenta caminhos para ruptura do ciclo de violência por meio de processos formativos e possibilita a interação com a plataforma permitindo indicar programas de apoio que ainda não estão no site (UNFPA, 2021).

De acordo com Santos et. al, 2018, no atendimento a vítimas de violência os profissionais de Buíque seguem os seguintes passos: Acolhimento e primeiro contato com a equipe de enfermagem, após isso é feito a notificação compulsória e a realização do atendimento médico, o qual encaminha a vítima para a delegacia especializada em atendimento à mulher $\mathrm{e}$ dependendo do tipo e da forma que ocorreu o ato violento para os demais serviços da rede de apoio. 
O serviço de saúde não tem um fluxograma específico definido para atendimento a essas mulheres vítimas de violência, e este deveria ser o ponto de partida para a resolução de problemas nessa esfera, é necessário considerar as singularidades que facilitem o acesso e continuidade dessas mulheres no atendimento para acompanhamento e prestação de serviço centrados na vítima (Martins et al, 2016).

A Norma Técnica para Atenção Humanizada às Pessoas em Situação de Violência Sexual, recomenda que os atendimentos às vítimas de violência sexual nos serviços de saúde do Brasil, sigam as seguintes etapas: acolhimento, registro da história, exames clínicos e ginecológicos, coleta de vestígios, contracepção de emergência, profilaxias para HIV, IST e Hepatite $\mathrm{B}$, comunicação obrigatória à autoridade de saúde em $24 \mathrm{~h}$ por meio da ficha de notificação da violência, exames complementares, acompanhamento social e psicológico, e seguimento ambulatorial (Ministério da Saúde, 2015).

Alguns resultados apresentaram as ESF's como o primeiro contato da vítima com os serviços de saúde após o ato violento, por isso é necessário que prestem um acolhimento empático e adequado as essas mulheres. (Borburema, et al, 2017; Cavalcanti et al, 2020). Já outros estudos (Vasconcellos \& Cecchetto, 2017; Oliveira e Moreira, 2016; Garcia, 2016) abordaram o assunto de forma a entender as DEAM's como porta de entrada principal ao acesso à justiça e a rede de atendimentos. A fluidez dessa continuidade irá depender das instituições interligadas. Nas DEAM's e nas instituições de saúde, ainda predominam por parte de alguns profissionais, conceitos pré-estabelecidos baseados no histórico social e de gênero o que corrobora para que as mulheres descontinuem o seguimento do fluxo de atendimento.

É observado que os fluxogramas existentes de atendimentos se diferenciam entre si, com atendimentos específicos para ocorrências imediatas ou remotas, com ou sem gravidez decorrente da violência. A principal diferença se dá pela gravidez, por demandar acompanhamento especial à vítima, devido a sua maior complexidade, havendo ou não o desejo de interrupção. Mesmo necessitando de fluxogramas diferentes, ambas as situações devem ter acompanhamento especializado (Nunes \& Morais, 2017).

Acerca do tratamento de saúde, muitas vezes as portas de entrada serão os prontos-socorros nos hospitais, de onde as vítimas são encaminhadas para os serviços especializados que darão seguimento a assistência especifica a mulher. Para isto teremos: os cuidados quanto à profilaxia de infecções sexualmente transmissíveis (IST's) e gravidez indesejada; a realização de exames, como o exame físico que compõe provas para o sistema judicial e identifica lesões que requerem tratamento, além de outros exames complementares; as situações de gravidez, tendo a mulher o direito assegurado ao aborto; a assistência multiprofissional do serviço (medicina, enfermagem, psicologia e serviço social) e a interface com outros que vierem a ser necessários, como das áreas policiais e judiciais. (Nunes \& Morais, 2017).

Segundo o estudo realizado no PRAVIVIS, do hospital geral de Caxias do sul, RS, Brasil notou-se que em 63,8\% dos casos as vítimas foram atendidas nas primeiras 72 horas após a violência sexual e em 34,2\% receberam a medicação profilática completa. No entanto as vítimas que já usam regularmente métodos contraceptivos não recebem a anticoncepção de urgência, estas correspondem a 15,6\% dos casos. Observa-se ainda, o número considerável de pacientes que não recebem nenhum tipo de medicação $(35,8 \%)$, visto que chegaram ao serviço de saúde após as 72 horas da violência sexual. Há ainda os casos das vítimas que não evidenciaram nenhuma lesão extragenitais, genitais ou contato da vítima com secreções do agressor, estas também não fazem uso da medicação profilática (Madi et. al, 2010).

Estudo realizado em um centro de referência de Curitiba, evidenciou que a contracepção de emergência foi realizada em 64,77\% das vítimas, provavelmente atrela-se esse fato às mulheres estarem em idade reprodutiva, estando 53,46\% entre 12 a18 anos e 43,47\% entre 19 a 59. A indicação do PEP ao HIV ocorre em casos onde houve contato com mucosas vaginal, oral e anal, e no estudo em questão houve indicação em $76,4 \%$ dos casos. A partir daí as vítimas foram encaminhadas para dar seguimento ambulatorial de infectologia, houve evasão de quase 60\% das vítimas, apenas 40,5\% (394) voltaram para o primeiro atendimento (Trigueiro et al, 2015). 
Uma gravidez indesejada acarreta reflexos negativos e prejuízos a vida emocional em grandes dimensões, prejudica relacionamentos afetivos, gera ansiedade, lembranças intrusivas, sensações corporais que retornam diariamente, depressão, transtornos do sono, culpa, vergonha e prejuízos no estabelecimento de relações interpessoais (Nunes \& Morais, 2016).

Nunes \& Morais, 2016, apresentaram experiências vivenciadas por mulheres que engravidaram em decorrência da violência sexual, onde todas demonstraram interesse em interromper a gestação. Desde o desejo inicial até após o ato do aborto as vítimas se mantiveram firmes, tendo como principais justificativas para isso a forma em que se deu a gravidez e a impossibilidade de dissociar a criança da imagem do agressor e da violência. O que torna inviável cumprir com as demandas adjuntas à maternidade e negativa a experiência de vida da criança.

Embora a experiência e apoio profissional tenha sido positiva no centro de referência onde ocorreu a pesquisa, evidencia-se ainda uma visão negativa por parte dos profissionais nos serviços de saúde quando a assistência cursa com a interrupção legal da gravidez, o que corrobora com a resistência no contato. As instituições deveriam se manter imparcial no processo de decisão, desta forma poderia evitar agravos de saúde como abortamentos clandestinos e realizar o adequado acompanhamento e suporte para as vítimas (Nunes \& Morais, 2016).

Segundo o estudo Borburema et.al, 2017, 58 \% das mulheres não obtiveram direcionamento aos outros profissionais de saúde, as demais tiveram direcionamento para equipe multiprofissional: médico da APS (médico de família e comunidade ou clinico geral) neurologista, acupunturista, psicólogos e psiquiatra. Em $90 \%$ dos casos não houve encaminhamento para outras instituições, somente 3,4\% foram destinados para CREMV (Centro de Referência de Atendimento à Mulher em Situação de Violência) / Delegacia da Mulher, 3,4\% para INSS e para a Secretaria Municipal de Assistência Social.

No que tange os anos de 2009 a 2013, os seguintes números foram registrados para encaminhamentos feitos pelo setor saúde foram a nível ambulatorial contabilizando 15.824/72,6\% e evoluíram direto para alta 16.879/77,2\% (Moreira et al, 2015).

Como forma de estabelecer um fluxo de atendimento, o Estado do Rio Grande do Sul, em novembro de 2013 promulgou as Leis $\mathrm{n}^{\circ} 14.352$ e 14.353, que instituía o atendimento integrado através da humanização da assistência e dos estabelecimentos de fluxos de encaminhamento. Ainda nesse mesmo mês foi criado o Comitê Lilás, com a finalidade de acompanhar a implementação do Protocolo de Fluxos da Rede Lilás- Rede de Enfrentamento e Atendimento Especializado às Mulheres em Situação de Violência (Berwanger, 2020).

A partir de 2011, a notificação de violência passa a ser obrigatória tanto em âmbito público como privado. Com a implementação da notificação compulsória observou-se o aumento nas notificações de estupro em 66,1\% entre os anos de 2011 e 2014. Apesar da melhoria ainda existe dificuldade no sistema para conseguir total êxito, um exemplo é o Sistema de Informação de Agravos de Notificação (Sinan) não estar distribuído homogeneamente pelo país (IPEA, 2017).

Considerando os achados deste estudo foi possível evidenciar a subnotificação como uma das principais problemáticas citadas. Dos 58 artigos analisados 32,75\% relacionaram a subnotificação como um dos obstáculos no enfrentamento à violência sexual. Tal fato demonstra a necessidade de intervenções que possibilitem alcançar a efetividade na realização dos registros, pois somente assim serão apresentados dados estatísticos capazes de dimensionar a real incidência da violência sexual no cotidiano das mulheres.

As variáveis consideradas na composição da ficha de notificação de violência sexual, são: unidade da federação, faixa etária, escolaridade, raça, local de ocorrência, forma de agressão, característica do agressor e encaminhamentos realizados pelo setor saúde (Moreira et al., 2015), A notificação na violência sexual é imediata visando agilizar o atendimento da vítima e seu acesso aos procedimentos e medidas protetivas necessárias (Carnevalle et al, 2019).

Entre os períodos de 2009 a 2013 foram notificados 21.871 registros de violência sexual, apresentando gradativo aumento nas notificações respectivamente. Ao analisar a distribuição dos registros por unidade de federação elencou-se as seguintes unidades federativas com maiores taxas de notificação por ano: 2009 - Roraima $(7,7)$ e Mato Grosso do Sul $(3,6)$; 
Research, Society and Development, v. 10, n. 14, e344101422427, 2021

(CC BY 4.0) | ISSN 2525-3409 | DOI: http://dx.doi.org/10.33448/rsd-v10i14.22427

2010 - Roraima (10,8) e Rio de Janeiro (11,1); 2011 - Acre (33,4) e Mato Grosso (10,3); 2012 - Acre (54,5) e Piauí (24,9); 2013 - Acre $(70,9)$ e Piaú $(19,8)$. A região norte foi quem mais notificou casos de violência sexual (Moreira et al., 2015).

Foram registrados em 2014 um total de 47.646 estupros no Brasil, com subnotificação estimada em 35\%, o SINAN registrou 17.781 atendimentos a mulheres vítimas de estupro em 2015, no entanto deve-se levar em consideração que $40 \%$ dos municípios brasileiros ainda não notificavam. Em pesquisa realizada pelo Fórum Brasileiro de Segurança Pública no ano de 2014, 90\% das entrevistadas relataram ter medo de sofrer agressão sexual. Garcia relata ainda que os riscos estimados das mulheres serem estupradas no Rio de Janeiro em 2016 se equipara ao de um homem ser assassinado por arma de fogo e é ainda maior comparado ao risco de infecção por dengue (Garcia, 2016).

Pelos dados trazidos por Silva e Oliveira, 2016 nota-se que entre 2009 e 2012 foram registrados 1.924 casos suspeitos ou confirmados de violência contra mulheres, em 31 distritos residenciais no DF, destes a violência sexual foi a segunda mais frequente, totalizando $22,5 \%$ dos casos.

Segundo Trigueiro et al. 2015, entre os anos de 2009 e 2013 foram notificados 1.272 casos como suspeitos de violência sexual, sendo as mulheres $94,65 \%$ do total de pessoas atendidas. A maior incidência dessas agressões ocorreu no período noturno com mais $47 \%$ do total, entre as $19 \mathrm{hs}$ e $07 \mathrm{hs}$ do dia seguinte. Dos 1.272 casos, ocorreu penetração via vaginal em 1.164. Com base nos dados percebemos que em um período de cinco anos nem 2.000 notificações foram realizadas, o que acaba por nos deixar em dúvidas quanto à possibilidade de subnotificações ou ocorrência de casos não notificados ou não reportados ao sistema de saúde, além da incidência desses casos se dar durante a noite e a madrugada, evidenciando maior demanda dos serviços durante esse período.

Segundo Neta et.al, 2020, a maior parte das notificações de abuso sexual, são feitas pela vítima, a qual é encaminhada para delegacia especializada, por conseguinte avaliada pela equipe multiprofissional. No entanto muitos casos não são notificados em detrimento ao medo que a vítima detém do acusado.

Garcia, nos mostra a falha nos sistemas de notificação e informações de dados a respeito da violência contra as mulheres e mais ainda sobre violência sexual. Segundo ele as estatísticas revelam uma pequena fração da ocorrência dos diversos tipos de violência, a qual as mulheres são submetidas em seu cotidiano. Por ser em sua maioria em âmbito privado e ser perpetrada por parceiro, familiares ou conhecidos, esses fatos ganham visibilidade somente em casos extremos ou ações que demandam intervenções do Estado e feminicídios (Garcia, 2016).

Ao comparar a notificação dos casos pelo setor saúde com os registros policiais, é notório a realidade de subnotificação. Os registros de um estudo realizado em 2011 pela polícia civil no DF, identificou 6.288 denúncias de violência contra a mulher. Dados espantosamente superiores aos apresentados pelo setor saúde em 4 anos, que notificou 1.924 casos. Não obstante, devemos ressaltar que nem todos os casos de violência necessariamente levam a lesões passíveis de assistência à saúde, o que também poderia justificar o maior número de notificações policiais (Silva e Oliveira, 2016).

No Brasil, as dificuldades referentes à notificação dos casos de violência contra a mulher são a escassez de regulamentos que firmem os procedimentos técnicos, as falhas na identificação da violência no serviço de saúde, a ausência de mecanismos legais de proteção aos profissionais encarregados de notificar e o sigilo profissional (Souza \& Rezende, 2018).

É imprescindível que a notificação seja realizada de maneira adequada, pois este é o principal instrumento estatístico que permite aumentar a visibilidade de todos os tipos de violência vivenciada pela mulher, para desta forma torna-los reconhecido com um grave problema de domínio público (Garcia, 2016).

Em pesquisa realizada com a Equipe de Saúde (ESF) de algumas Unidades Básicas de Saúde (UBS) de Teresina, os profissionais relataram que a sua formação não contribuiu muito para o atendimento voltado a mulheres vítimas de violência e que não houve cursos de capacitações no início da sua atuação na ESF. Ainda afirmaram não ter uma tarefa específica na unidade que abrangesse essa demanda. E o pouco de assistência que tem voltada a essas vítimas ainda sofre dificuldades, tanto a respeito 
da formação inadequada dos profissionais quanto a falta de suporte multidisciplinar funcional. Demonstra-se que há boas campanhas contra a violência e a conscientização voltadas a sociedade, entretanto não há ainda orientação suficiente quanto a atuação específica para cada profissional de saúde, fazendo com que se sintam incapazes de conduzir adequadamente estes casos. Atualmente, algumas organizações não-governamentais feministas começaram a produzir material didático com orientações sobre o tema e a oferecer treinamentos aos profissionais de saúde. Contudo, ressaltou-se o pouco preparo na graduação acadêmica assim como no serviço na condução da assistência qualificada a mulheres vítimas de violência (Villa et al., 2018).

De acordo com os registros dos prontuários de uma APS em Florianópolis, 58\% foram registrados por médicos (médicos da APS, psiquiatra e homeopata), 24\% por enfermeiros, 6,9\% por psicólogos, 3,4\% por agente comunitário de saúde, 3,4\% por assistente social e 3,4\% por fonoaudiólogo. Grande parte dos registros ocorreram na APS, em Centros de Atenção Psicossocial (CAPS), em Centro de Atenção Especializada (Policlínica) e a minoria em atendimento em visita domiciliar (Borburema, 2017).

Curia et al, 2020, nos trouxe como resultado a percepção de poucos casos acompanhados pela equipe multidisciplinar e a falta de entendimento pelos profissionais de saúde da diferenciação entre notificação e denúncia. Os artigos que propuseram avaliar a rede de enfrentamento são minorias e conclusivos de que são precários os recursos humanos especializados, a infraestrutura e a articulação de serviços que o compõem.

Os profissionais entendem a necessidade de realizar a notificação compulsória em sua prática, entretanto, reconhecem a subnotificação e desta feita a corroboração para que a violência continue. Não se pode apenas culpabilizar os profissionais, mas aprofundar-se sobre os fundamentos da subnotificação e consumir energias em estratégias para alterar essa realidade (Cruz et al., 2015).

Evidencia-se a importância do ACS no processo de investigação e identificação aos riscos ou casos consumados de violência, pois eles pertencem a comunidade, conhecem a realidade local e tem vínculos que facilitam a escuta ativa das usuárias dos serviços de saúde. Ainda é possível observar muito desconforto por parte dos profissionais em abordar o assunto. Na prática médica identifica-se ainda abordagem biologicista como prática dominante, o que corrobora as limitações do serviço. Outro entrave exposto foi o horário de atendimento das UBS, que não atende a demanda da maioria das vítimas de violência, pois as mesmas ocorrem principalmente à noite (Martins et al, 2016).

O mau desempenho dos profissionais de saúde em investigar possíveis casos, muitas vezes utilizando como justificativa a falta de tempo, a dificuldade em expor o assunto e a ausência ou falta de conhecimento dos serviços disponíveis para os apoiar, foi visto como um dos impasses para o fluxo não correr como esperado. Apesar do aumento nos números registrados de vítimas de violência ainda se tem como obstáculos a presença da subnotificação e a omissão por parte das mulheres. A ausência de protocolos específicos sugere falta de regulamentação técnica e de parâmetros científicos, o que contribui para que os profissionais tenham a percepção que estão isentos de tal responsabilidade (Cavalcanti et al., 2020).

Para organizar os atendimentos foi evidenciado a necessidade da elaboração de protocolos, que favoreçam o atendimento rápido, auxiliem o profissional nas orientações e que tenham encaminhamentos pertinentes nos casos de violência sexual. Observou-se a falta de algumas especialidades profissionais para complementar o atendimento integral as essas mulheres, o que leva a outros profissionais de saúde ultrapassarem as fronteiras da sua profissão para preencher essas lacunas e oferecer um cuidado e atendimento adequado as necessidades das pessoas (Trentin et al., 2018).

Podemos perceber o quão falho ainda é o sistema de justiça no tange às DEAM's e os profissionais que ali estão para gerir esse trabalho. Algumas decisões judiciais pautadas no inquérito policial na percepção do estado físico e emocional que os policiais tiveram a respeito dessas mulheres (Oliveira e Moreira, 2016).

Os relatos apresentados pelas participantes, muitas vezes, atestaram serviços isolados, estruturas despreparadas e atendimentos desqualificados profissionalmente para atender as mulheres em situações de violência. Observou-se que o outro 
setor mais procurado da rede de atendimento à mulher foi o setor policial, o qual por parte das entrevistadas houve bastante reclamações por negligências e desrespeitos nos atendimentos. Somado a isso, houve contestação a respeito da eficácia da Medida Protetiva de Urgência (Soares e Lopes, 2018).

Por meio das narrativas trazidas, nota-se posturas sexistas ainda por parte de profissionais que responsabilizam e culpam as atitudes da mulher que não consegue romper a situação de violência e a colocam como juíza da punição para o agressor. No entanto, para que mulheres em situação de violência rompam com essa situação que muitas vezes é perpetrada pelo pai de seus filhos, é necessária libertação de um imaginário social em que é inserida e apropriada culturalmente, como provedora da harmonia e defesa do lar, além dos julgamentos públicos e entre outros inerentes. Denotou que ainda há a crença de que o homem foi induzido a agir violentamente respondendo a ações da mulher, como exemplos trazidos: "provocaram até que se perdesse a paciência, por efeito de forte emoção e até defesa de sua honra" (Oliveira e Moreira, 2016).

Percebe-se ainda abordagens ou acolhimentos estreitamente interligados ao machismo estrutural e suas peculiaridades. Fator que desencoraja mulheres vítimas a darem seguimento as suas denúncias, por serem contestadas quanto a veracidade da sua queixa ou responsabilizada pela ação do agressor o que faz com que se sintam muitas vezes ridicularizadas. Por essa demanda ser subestimada e haver negligências nos atendimentos por muitos profissionais o acesso e o fluxo de assistência acabam tornando-se ineficaz.

Embora muitos avanços já tenham sido obtidos é imprescindível que a violência contra a mulher seja reconhecida como violação dos direitos humanos e a criação desse equipamento público seja coerente assegurando os direitos civis da mulher, que as equipes interdisciplinares passem por repescagem, recapacitação, e estratégias de educação continuada afim de prestar essa atenção como de fato é proposto. Fica evidente o despreparo desses agentes além da imposição de seu juízo de valor e reprodução de atitudes preconceituosas, que corroboram ainda mais com a situação de vulnerabilidade e violência institucional (Oliveira e Moreira, 2016).

Estudo realizado com 35 profissionais em Salvador destacou que não houve preocupação com a abordagem da temática violência contra a mulher nem na graduação quanto na especialização. A formação acadêmica no modelo cartesiano centrado na doença não prepara os profissionais para reconhecer tais agravos. Os reflexos da insuficiência na formação acadêmica podem ser constatados pelos relatos de dificuldades dos profissionais em atender mulheres em situação de violência (Cordeiro et al, 2015).

Em situações que não predomina queixas caracterizadas pelo adoecimento biológico, com sintomas precisos a patologias costumeiras, ressalta-se obstáculos comunicacionais. Tal premissa termina por inviabilizar o diagnóstico de situações de violência, o que culmina no insucesso da assistência. Para que se consiga desvelar situações de violência sexual é fundamental que os profissionais tenham interesse e desvinculação ao juízo de valor, com atitude de não revitimização e apoio a mulher (D'oliveira \& Schraiber, 2013).

É possível salientar que os profissionais nos serviços lidam mal com a violência em questão, dado que, são identificados nos comportamentos pessoais problemas comuns à normas culturais. Para além do não saber como conduzir e dar seguimento dentro da rede, depara-se ainda no não reconhecimento da situação de violência como relevante ao campo de atuação em saúde (D’oliveira \& Schraiber, 2013).

$\mathrm{O}$ artigo por meio de seus resultados alarmantes nos traz evidências quanto a necessidade de preparar os profissionais da área de saúde para lidar com essa demanda. Que seja desde a graduação ou por meio de educação permanente ou capacitação ofertada pelo ministério da saúde para que as propostas da política nacional sejam eficazes. É imprescindível, trazer a luz dessa discussão a indispensabilidade do profissional tanta na esfera primária quanto nas esferas especializadas, ter competência suficiente para receber, investigar, identificar, acolher, notificar, conduzir, encaminhar/contra-referenciar e orientar as vítimas 
que buscarem esse serviço, além de fazer captura daquelas que não conseguirem realizar denuncia verbalmente a ocorrência da violência (Baptista et al., 2015).

A pesquisa foi realizada com enfermeiros, mas não obstante a isso, devemos estender seus resultados aos profissionais de saúde, bem como demais profissionais e áreas atuantes nessa temática. Tendo em vista que os aspectos de violência sexual nem sempre deixam marcas físicas, estando ainda esse presente em 'poucos casos de violência sexual, por assim tal fato atesta o silêncio que predomina em tais situações e agrava essa ameaça (Baptista et al., 2015).

Trazendo a discussão para problemática do acesso aos serviços de atendimento a mulheres vítimas de violência sexual, evidencia-se a falta de informações sobre a existência e o direito de acesso aos serviços, os entraves na articulação na rede de atendimento e o desconhecimento por parte dos próprios profissionais sobre os serviços especializados. São imensas as adversidades inerentes ao atendimento. O serviço deve ser garantido pelo Estado de forma intersetorial e qualificada, por meio da capacitação dos profissionais atuantes desde o atendimento nos serviços primários até os especializados; além de elencar o quão fundamental é para a assertividade, que o profissional esteja firmado sob conceitos bioéticos, que abram mão de seu juízo de valor e preconceitos estabelecidos conforme suas crenças pessoais e religiosas.

De acordo com a pesquisa Silva et.al ,2019, a precarização da estrutura física das instituições, contribui para a revitimização e enfraquecimento da assistência prestada. A carência de recursos materiais e humanos qualificados impactam diretamente no processo dos inquéritos de investigação e na implementação de medidas protetivas de urgência, dessa forma dificulta o acesso da vítima. Estes fatores vulnerabilizam e desencadeiam a exposição da mulher à violência institucional e enfraquecem a proposta de atenção na rede.

Vale ressaltar que mesmo com a ampliação dos equipamentos sociais destinados à atenção da mulher e o progresso no campo jurídico venham estimulando a busca dos serviços e o registro de denúncias pelas mulheres violadas, ainda são poucos os relatos de violência sexual. Tal fato justifica-se pela insegurança das vítimas em acessar as instituições, o medo de não terem suas demandas atendidas e reviverem a violência psicológica, gerando assim uma verdadeira peregrinação na busca por assistência e direitos contra a violência sexual (Silva et.al ,2019).

O estudo ainda revela a necessidade de o governo em criar medidas de educação em saúde, nas mídias, usando a internet como veículo de propagação de informação para o enfrentamento do abuso sexual (Silva et.al ,2019).

De acordo com Martins et al., 2016, é válido redimensionar o acolhimento espacial nas estruturas físicas das UBS’s afim de permitir que essas mulheres tenham melhor condição de privacidade e segurança para estar mais à vontade ao se deportar ao serviço (Martins et al, 2016). Em se tratando ainda do acolhimento deve-se ponderar que a triagem é um de seus constituintes primordial no atendimento à mulher, visando não somente possibilitar que ela fique segura e tenha confiança para relatar sua queixa, mas principalmente perceber na prática a conduta pontual e compatível com o serviço assistencial correto. Pois quando essa busca não é compatível acaba não ocorrendo o seguimento do caso. Influenciando negativamente na transversalidade da atenção (D'oliveira \& Schraiber, 2013).

Além disso, foi encontrado nesta pesquisa obstáculos no funcionamento da rede, como a falta de retorno dos encaminhamentos e a interrupção da continuidade dos acompanhamentos em outros serviços, além da ausência ou má qualificação profissional e má qualidade dos equipamentos (Souto \& Castelar, 2020).

Conforme Trigueiro et al, 2015 apresentou houve evasão de quase 60\% das vítimas e apenas 40,5\% (394) voltaram para o primeiro atendimento. Entre as que compareceram no primeiro atendimento, somente $19,54 \%$ estiveram presentes no quarto retorno. No ano de 2012, iniciaram o atendimento de 89 vítimas e destas apenas 8 finalizaram o tratamento. Constata-se um número muito grande de abandono do tratamento o que torna necessário a compreensão do porquê disso estar ocorrendo para que se possa intervir, incentivar, bem como trabalhar mais em estratégias dentro e fora do serviço sobre a importância de dar seguimento e concluir o tratamento. Com interesse de evitar sequelas psicossociais emocionais das vítimas. 
As percepções de modo geral, apontam o reconhecimento de que se é preciso aprimorar a infraestrutura existente, preparar e amparar os profissionais para humanizar os atendimentos. Além de ser fundamental criar serviços especializados e investir em prevenção (Vieira \& Hasse, 2017).

Portanto, salienta-se ainda que há necessidade de normatizar os procedimentos e encontrar estratégias que alinhem os conhecimentos existentes com ações preventivas. Enfatizando que cada caso requer um fluxo assistencial especifico que trace um plano terapêutico individualizado de acordo com as necessidades requeridas (Carnevalle et al., 2019).

Levando em consideração os dados mencionados e expostos abordados no estudo, é nítido a urgência de políticas públicas e leis verdadeiramente efetivas para a proteção da mulher, juntamente com uma formação continuada e com instrumentalização dos profissionais (Trentin et al., 2018).

Várias são as adversidades ao atendimento às vítimas de violência, como barreiras encontra-se: a falta de infraestrutura, a inexistência de um local especifico que oferecesse todos os serviços, a dificuldade no estabelecimento de fluxos de atendimentos e o despreparo para lidar com o tema de violência. Por fim, o fato de poucos trabalhos preventivos terem sido desenvolvidos supõe-se que tantos casos chegam no serviço especializados porque a prevenção não está sendo efetiva e se não for realizada de forma adequada nunca haverá serviço suficiente. Há o reconhecimento de que é preciso humanizar os atendimentos e melhorar a infraestrutura, além de implementar alguns serviços especializados, principalmente àqueles previstos em lei (vara especializada, centro de referência e serviço de reeducação dos autores de violência) (Vieira \& Hasse, 2017).

\section{Conclusão}

Através deste estudo pode-se elencar lacunas na identificação dos casos de violência sexual, no acolhimento e atendimento, tanto no âmbito da saúde quanto no judiciário. Além da falta de informação do serviço ofertado, há ainda o preconceito estagnado. A violência sexual contra a mulher e todas as suas vertentes e dimensões são problemas de saúde pública muito sérios que precisam ser debatidos desde a graduação, para melhor capacitar os profissionais a fim de garantir a eficácia das redes de atendimento em todas as suas esferas.

A dificuldade das mulheres em acessar os serviços, se dá pela precariedade na propagação e veiculação de informações a respeito de quais são os serviços ofertados, bem como suas localizações e tipos de atendimento. É importante salientar ainda que muitas vítimas têm suas queixas ridicularizadas ou negligenciadas e sofrem medo de represálias advindas do acusado, da sociedade e dos próprios profissionais, em consequência de sua denúncia.

No que tange a identificação dos casos de violência sexual na estratégia de saúde da família (ESF) nota-se a necessidade de maior atenção dos profissionais e empenho para identificar possíveis casos dentro da comunidade. Os profissionais devem ser melhor capacitados para investigar e abordar questões de violência sexual. Evidenciou-se o despreparo dos profissionais em conduzir as vítimas, além de não as referenciar adequadamente aos serviços especializados sem que as mesmas acabem por sofrer revitimização. Sendo assim o fluxo de atendimento é prejudicado e se mostra ineficaz. Não há um padrão de fluxo assistencial preconizado a nível nacional ou protocolos que facilitem o manejo individualizado dos casos. É formidável que se pense em um local específico de abrangência médica e judicial 24 horas, afim de possibilitar o acesso de forma direta, assertiva e prestação de assistência integrada sem que ocorra peregrinação dessas mulheres.

A subnotificação e as notificações incompletas corroboram para a não estratificação real dos números de casos, diminuindo a visibilidade e a não exposição do agravo como sendo problema de saúde pública. Tais premissas dificultam a busca por estratégias capazes de fortalecer o enfrentamento contra a violência sexual, dados estatísticos que demonstre sua real magnitude e a implementação de medidas preventivas.

Por fim, foi possível ainda relacionar os fatores supracitados acima com as lacunas existentes na graduação dos 
profissionais. É evidente a necessidade de trabalhar a temática de violência sexual contra mulheres como disciplina regular obrigatória para esses profissionais, afim de torná-los agentes ativos, sensibilizados, aptos a lidar com as vítimas desde a fase de identificação até o encerramento do acompanhamento de maneira humanizada. Incentivar estudos que abordem essa temática é importante para avaliar, atualizar e discutir sobre melhorias em como conduzir mulheres vítimas de violência sexual no país.

\section{Referências}

Arrais, A.; Zerbini, E. C.; Jota, F. S. S. V. B. O.; Almeida, R. R. M.; Costa, A. R. C. \& Silva, K. T. (2020). Desafios para a implantação da cadeia de custódia de vítimas de estupro no Distrito Federal. Esc. Anna Nery, Rio de Janeiro, 24(1):e20190101.

Baptista, R.S.; Chaves, O. B. B. M.; França, I. S. X.; Sousa, F. S.; Oliveira, M. G. \& Leite, C. C. S. (2015). Violência sexual contra mulheres: a prática de enfermeiros. Rev Rene., 16(2):210-7.

Berwanger, A, D. (2020). Perfil dos casos de violência contra a mulher notificados no município de Eldorado do Sul, Rio Grande do Sul, entre 2010 e 2018. TCC (Especialização em Saúde Pública) - Escola de Saúde Pública em cooperação com a Universidade Estadual do Rio Grande do Sul. Rio Grande do Sul, $(\mathrm{s} / \mathrm{n}): 76$.

Borburema, T. L. R.; Pacheco, A. P.; Nunes, A. A.; Moré, C. L. O. O. \& Krenkel, S. (2017). Violência contra mulher em contexto de vulnerabilidade social na Atenção Primária: registro de violência em prontuários. Rev Bras Med Fam Comunidade, 12(39):1-13. http://dx.doi.org/10.5712/rbmfc12(39)1460

Carnevalle, C. V.; Schimidt, T. C. G; Moraes, M. A.; Shirassu, M. M. \& Valencich, D. M. O. (2019). Notificações de violências contra a mulher adulta no Estado de São Paulo em 2014. BEPA, São Paulo.

Cavalcanti, G. M. B.; Amorim, A. V. B.; Queiroz, G. S.; Cruz, N. M.; Costa, R. L. \& Bezerra, K. F. O. (2020). Violence against women in the single health system. Rev Fun Care Online, 12:146-154.

Cordeiro, K. C. C.; Santos, R. M.; Gomes, N. P.; Melo, D. S.; Mota, R. S. \& Couto, T. M. (2015). Formação profissional e notificação da violência contra a mulher. Revista Baiana de Enfermagem, [S. 1.], 29(3):209-217.

Cruz, N. M.; Tavares, V. S.; Gomes, N. P.; Silva Filho, C. C.; Magalhães, J. R. F. \& Estrela, F. M. (2015). Meanings of the reports of violence against women: a descriptive study. Online braz, jurs, 14 (2):144-50.

Curia, B. G.; Dias, V.; Zamora, J. C.; Ruoso, A.; Ligório, I. S. \& Habigzang, L. (2020). Produções científicas brasileiras em Psicologia sobre violência contra mulher por parceiro íntimo. Psicologia: Ciência e Profissão, 40, 1- 19.

D’Oliveira, A. F. P. L., \& Schraiber, L. B. (2013). Mulheres em situação de violência: entre bapt críticas e redes intersetoriais de atenção. Revista De Medicina, 92(2), 134-140.

Fundo de População das Nações Unidas (UNFPA). (2021). Plataforma voltada a mulheres em situação de violência registra 3,7 mil acessos em dois meses. Notícia. https://brazil.unfpa.org/pt-br/news/plataforma-voltada-mulheres-em-situa\%C3\%A7\%C3\%A3o-de-viol\%C3\%AAncia-registra-37-mil-acessos-emdois-meses

Garcia, L.P. (2016). A magnitude invisível da violência contra a mulher. Epidemiologia e Serviços de Saúde [online], 25(3):451-454.

Gonçalves, H.A. (2005). Etapas de realização de uma pesquisa científica. In: _. Manual de metodologia e pesquisa científica. 1. Ed. São Paulo: Avercamp. cap. 5 , p. 1 .

Instituto de Pesquisa Econômica Aplicada (IPEA). (2017). Estupro no Brasil: vítimas, autores, fatores situacionais e evolução das notificações no sistema de saúde entre 2011 e 2014. Rio de Janeiro.

Lei $\mathrm{N}^{\mathrm{o}}$ 10.778, de 24 de novembro de 2003. (2003). Diário Oficial da União - Seção 1 (2003). Acesso 26 de out. 2021. http://www.planalto.gov.br/ccivil_03/leis/2003/110.778.htm

Lei $\mathrm{n}^{\mathrm{o}}$ 12.845, de $1^{\mathrm{o}}$ de agosto de 2013. (2013). Diário Oficial da União, Seção 1, p. 1, Brasília, DF. https://dspace.mj.gov.br/bitstream/1/3427/1/LEI_2013_12845.pdf

Martins, L. C. A.; Silva, E. B.; Costa, M. C.; Colomé, I. C. S.; Fontana, D. G. R. \& Jahn, A. C. (2016). Violência contra mulher: acolhimento na estratégia saúde da família. Ciência, Cuidado \& Saúde, 15(3), 507-514. https://dx.doi.org/10.4025/cienccuidsaude.v15i3.31422

Mendes, K. D. S; Silveira, R. C. C. P \& Galvão, C. M. (2008). Revisão integrativa: método de pesquisa para a incorporação de evidências na saúde e na enfermagem. Texto Contexto Enferm. Florianópolis, v. 17.

Ministério da Saúde. (2004). Portaria $\mathrm{n}^{\mathbf{0}}$ 936, de 18 de maio de 2004. Diário Oficial da União, Poder Executivo, Brasília, DF. <http://portal.saude.gov.br/portal/arquivos/pdf/portaria936.pdf>.

Ministério da Saúde. (2006). Portaria No 1.356/GM, de 23 de junho de 2006 - Institui incentivo aos Estados, ao Distrito Federal e aos Municípios para a Vigilância de Violências e Acidentes em Serviços Sentinela com recursos da Secretaria de Vigilância em Saúde (SVS). Publicada no Diário Oficial da União Seção 1 - Número 120 de 26/06/2006. Brasília/DF.

Ministério da Saúde. (2010). Secretaria de Vigilância em Saúde. Secretaria de Atenção à Saúde. Política Nacional de Promoção da Saúde. 3. Ed. Brasília: Ministério da Saúde, 2010. 
Ministério da Saúde. (2010b). Secretaria de Atenção à Saúde. Departamento de Ações Programáticas Estratégicas. Linha de cuidado para a atenção integral à saúde de crianças, adolescentes e suas famílias em situação de violências: orientação para gestores e profissionais de saúde / Ministério da Saúde. Secretaria de Atenção à Saúde. Departamento de Ações Programáticas Estratégicas. - Brasília: Ministério da Saúde.

Ministério da Saúde. (2012). Secretaria de Atenção à Saúde. Departamento de Ações Programáticas Estratégicas Prevenção e tratamento dos agravos resultantes da violência sexual contra mulheres e adolescentes: norma técnica / Ministério da Saúde. Secretaria de Atenção à Saúde. Departamento de Ações Programáticas Estratégicas. - 3. ed. atual. e ampl., 1. reimpr. - Brasília: Ministério da Saúde.

Ministério da Saúde. (2015). Norma Técnica, Atenção Humanizada às pessoas em situação de violência sexual com registros de informações e coleta de vestígios. $1^{a}$ Edição, Brasília - DF.

Neta B.; Dias R. A.; Guimarães, P.S.O.; Farias., C.M.C. \& Santos, A.L. (2020). Mulheres vítimas de abuso sexual em um município da Amazônia. Revista Ciência, 6(3), 123-136.

Nunes, M. C. A. \& Morais, N. A. (2016). Estupro e gravidez: Relatos das vivências de mulheres antes e após o desfecho da gestação. Estudos de Psicologia, Natal, 21(4):468-476

Nunes, M. C. A. \& Morais, N. A. (2017) Gravidez decorrente de violência sexual: revisão sistemática da literatura. Arq. bras. psicol., Rio de Janeiro, 69(2): 88103.

Oliveira, C. M. \& Moreira, M. I. C. (2016). Os sentidos produzidos para a violência contra as mulheres a partir da perspectiva dos profissionais da delegacia especializada de atendimento a mulher de betim - Mg. Psicologia em Revista, Belo Horizonte, v 22(3): 729-748.

Organização Mundial da Saúde (OMS). (2005). Estudo multinacional da OMS sobre a saúde da mulher e a violência doméstica contra a mulher: resultados iniciais sobre prevalência, resultados de saúde e respostas das mulheres / autores: Claudia Garcia-Moreno ... [et al.]. Organização Mundial da Saúde. https://apps.who.int/iris/handle/10665/43309

Organização Mundial da Saúde (OMS). (2012). Prevenção da violência sexual e da violência pelo parceiro íntimo contra a mulher: ação e produção de evidência. Organização Pan-Americana da Saúde. ISBN 978-92-75-71635-9

Organização Pan-Americana de Saúde. (2021). Violência contra as mulheres. https://www.paho.org/pt/topics/violence-against-women

Oshikata, C. T.; Bedone, A. J.; Papa, M. S. F.; Santos, G. B.; Pinheiro, C. D. \& Kalies, AH. (2011). Características das mulheres violentadas sexualmente e da adesão ao seguimento ambulatorial: tendências observadas ao longo dos anos em um serviço de referência em Campinas, São Paulo, Brasil. Cad. saúde pública, 27(4): 701-713. Disponível em: https://pesquisa.bvsalud.org/bvsecuador/resource/pt/lil-587705.

Rosa, J. P. F; Oliveira, M. M.; Filho, M. M. O; Fernandes, C. E \& Oliveira, E. (2018). Violência sexual na região do ABC Paulista: retrato de 142 casos. Revista ABCS health sciences.

Santos, S. C.; Barros, P. A.; Delgado, R. F. A; Silva, L. V. L; Carvalho, V. P. S \& Alexandre, A. C. S. (2018). Violência contra a mulher: como os profissionais na atenção primária à saúde estão enfrentando esta realidade? Revista Saúde e Pesquisa.

Secretaria da Saúde. (2012). Ofício nº 4721/12 SESAU. Palmas, TO: Governo do Tocantins. Assunto: Resposta ao Ofício na 273/20121CPMIVCM

Silva, L. E. L. \& Oliveira, M. L. C. (2016). Características epidemiológicas de la violencia contra la mujer en el Distrito Federal, Brasil, 2009-2012. Epidemiol. Serv. Saude, Brasília, 25(2):331-342.

Soares, C. B.; Hoga, L. A. K.; Peduzzi, M.; Sangaleti, C.; Yonekura, T. \& Silva, D. R. A. D. (2014). Revisão integrativa: conceitos e métodos utilizados na enfermagem. Revescenferm USP, 48. DOI: 10.1590/S0080-623420140000200020

Soares, J. S. F. \& Lopes, M. J. M. (2018). Experiências de mulheres em situação de violência em busca de atenção no setor saúde e na rede intersetorial. Interface (Botucatu), Botucatu, 22(66):789-800.

Souto, V. S. \& Castelar, M. (2020). Psicólogas nos serviços especializados de atendimento às mulheres em situação de violência. Psicol. Estud., Maringá, 25:e44031.

Souza, M. T.; Silva, M. D. \& Carvalho, R. (2010). Revisão integrativa: o que é e como fazer. Einstein, 8(1 Pt 1):102-6.

Souza, T.M.C. \& Rezende, F.F. (2018). Violência contra mulher: concepções e práticas de profissionais de serviços públicos. Revista Estudos Interdisciplinares em Psicologia.

Trentin, D.; Vargas, M. A. O.; Pires, D. E. P.; Hellmann, F.; Brehmer, L. \& Leal, S. C. (2018). Attention to women in the situation of sexual violence in the bioethics perspective. Acta bioethica, 24(1), 117-126.

Trigueiro, T. H. et al. (2015). Vítimas de violência sexual atendidas em um serviço de referência. Cogitare Enferm. 20(2):249-56.

Vasconcellos, N. A. \& Cecchetto, F. R. (2017). Violência contra a mulher: uma análise dos desdobramentos da denúncia na cidade de vitória/es. Seminário Internacional Fazendo Gênero 11 \& 13th Women's Worlds Congress (Anais Eletrônicos), Florianópolis, ISSN 2179-510X.

Vieira, E. M. \& Hasse, M. (2017). Percepções dos profissionais de uma rede intersetorial sobre o atendimento a mulheres em situação de violência. Revista Interface (Botucatu): comunicação, saúde, educação.

Villa, V. L. B. N; Almeida, C. A. P. L; Santos, R. F; Lago, E. C; Tapety, F. I. \& Ribeiro, I. P. (2018). Assistência dos profissionais da Estratégia Saúde da Família na atenção à mulher vítima de violência. Revista Nursing. 